\title{
Sobre la crítica de la presentación noemática de la alteridad en M. Henry y el despliegue de una fenomenología de lo inaparente
}

Hernán Inverso*

Resumen: En vistas de una revisión general de la noción de sujeto, Michel Henry objeta, por un lado, su asociación con la representación y, por otro, el tratamiento de la alteridad presentada de manera intencional. Apunta con ello a mostrar en qué sentido la intencionalidad y la constitución no son las vías fenomenológicas adecuadas para dar cuenta del a priori universal de la experiencia de la alteridad. En rigor, la posición henryana sobre la crítica del sujeto no sólo pone en cuestión las presentaciones noemáticas de la alteridad, sino que se extiende hacia todo intento de dar cuenta del Otro desde una perspectiva que no sea auto-afectiva. Sin embargo, lo que a primera parece irreconciliable con el horizonte fenomenológico husserliano, puede resultar un aporte sustantivo en este mismo terreno. Examinaremos aquí la crítica a la postura husserliana para establecer una clave de lectura que no provoque una colisión entre ellas sino una sinergia que, retomando la potencia de los orígenes, despliegue un programa de investigación que abarque el estudio de todo el arco de la fenomenicidad.

Palabras clave: Sujeto, Intencionalidad, Alteridad, Fenomenología

On the criticism of the noematic presentation of alterity in M. Henry and the unfolding of a phenomenology of the unapparent

Abstract: Michel Henry questions the notion of subject and objects, on the one hand, its linkage with representation and, on the other hand, the description of alterity seen

\footnotetext{
* Licenciado y Doctor en Filosofía por la Universidad de Buenos Aires. Se desempeña como docente en la Cátedra de Gnoseología del Departamento de Filosofía (FFyLUBA) y como investigador en proyectos acreditados de la UBA, FONCyT y CONICET. Ha publicado libros, partes de libros y artículos en revistas nacionales e internacionales. Dirección electrónica: hernaninverso@icloud.com
} 
from an intentional perspective. He tries to show in what sense intentionality and constitution are not adequate phenomenological ways in the task to explain the universal a priori of the experience of alterity. Indeed, this critic of the notion of subject does not only questions the noematic presentations of alterity, but affects any attempt to account for the Other from a perspective that is not self-affective. However, what at first sight seems irreconcilable with the husserlian phenomenological horizon, can be a substantive contribution in this same area. We will examine here Henry's criticism on the husserlian position in order to provide a reading key that does not provoke a collision between them, but a synergy that, retaking the power of origins, deploys a research program that encompasses the study of the whole spectrum of phenomena.

Key words: Subject, Intentionality, Alterity, Phenomenology

Michel Henry considera que la crítica del sujeto desplegada durante el siglo XX por "casi la totalidad de movimientos del pensamiento contemporáneo" es una reiteración que no cesa de reproducir las objeciones a la subjetividad que ya se encontraban latentes en los orígenes cartesianos ${ }^{1}$. En este movimiento de repetición, Henry denuncia un silencio por parte de Husserl sobre el deseo en las modalidades concretas de nuestra Vida. Sentimiento de presencia o ausencia, soledad, amor o resentimiento no encontrarían un lugar preeminente en las Cartesianische Meditationen, y en esta falta se revelaría la carencia del enfoque óntico-noemático para dar cuenta de la alteridad.

El sujeto anclado en la representación y la alteridad asociada con la intencionalidad y la constitución no pueden, desde esta perspectiva, dar cuenta del a priori universal de la experiencia de la alteridad, aspecto al que se accede sólo desde una perspectiva auto-afectiva. En lo que sigue, estudiaremos la crítica que Michel Henry dirige contra la postura husserliana como punto de partida para mostrar que no hay entre estas posturas una incompatibilidad irreductible ni tampoco la posición henryana puede ser en sentido alguno una superación de la husserliana, sino que funciona como una clave que incita a la fenomenología a abarcar con su dispositivo todo el arco de la fenomenicidad incorporando aspectos que tradicionalmente quedaron en segundo plano.

\footnotetext{
${ }^{1} \mathrm{PhV1}, 37$.
} 


\section{Los supuestos del tratamiento husserliano de la alteridad}

En La esencia de la manifestación Henry se acercaba a la cuestión de la alteridad de modo formal, atendiendo al vínculo que remite la trascendencia a su esencia inmanente ${ }^{2}$. En este estadio de su reflexión, la alteridad se comprende como una modalización de la Vida inmanente sin significación ontológica autónoma. Sus rasgos se vinculan con la duplicidad del aparecer, que es, por un lado, constituido intencionalmente y, por otro, movimiento en la inmanencia ${ }^{3}$. Profundizando en esta vía, M. Henry aborda de manera frontal el problema de la intersubjetividad y propone una solución en el plano de la estricta inmanencia en Fenomenología material. El modo de acercarse a la cuestión implica una revisión crítica del análisis de la experiencia de la alteridad presentado por Husserl en la quinta de las Meditaciones Cartesianas. Esta restricción es claramente problemática, si se pretende, como hace Henry, proyectar una impugnación a la posición husserliana in toto, ya que importantes tratamientos sobre la alteridad se hallan en otros textos ${ }^{4}$.

Esta revisión detecta la presencia de tres supuestos que organizan el intento de impugnación general. El primero de ellos es que "sólo hay otro para mí si tengo experiencia de él, si, bajo cualquier forma o aspecto que sea, el otro me está dado, de modo que lo encuentro en mi propia Vida y, en cierta forma, es en mí (n'y a un autre pour moi que si j'en ai une expérience, que si, sous quelque forme ou sous aspect que ce soit, l'autre m'est donné, en sorte que je le trouve daris ma propre vie et que, d'une certaine façon, il est en moi)" ${ }^{5}$. Este primer supuesto rememora el argumento epicúreo sobre la muerte que es "nada para nosotros", dado que al implicar un contacto imposible no tendría siquiera su idea ${ }^{6}$. A juicio de Henry,

\footnotetext{
${ }^{2}$ M. Lipsitz, Eros y Nacimiento fuera de la ontología griega: Emmanuel Levinas y Michel Henry, Buenos Aires, Prometeo, 2004, p. 12.

${ }^{3}$ Ibidem, p. 19.

${ }^{4}$ Sobre este punto, véase, por ejemplo, A. Simón Lorda, "Vida y alteridad: ¿acercamiento entre E. Husserl y M. Henry”, en M. García Baró y R. Pinillas, Pensar la vida, Burgos, Comillas, pp. 175-192.

${ }^{5} \mathrm{PhM}, 137$.

${ }^{6} \mathrm{La}$ fórmula es transmitida por la Carta a Meneceo (Diógenes Laercio, X.124). La alusión cumple un papel importante en la discusión sobre los principios de la
} 
a eso apunta la afirmación husserliana que sostiene: "estas experiencias [i.e. la experiencia de la alteridad] y sus rendimientos son en efecto hechos trascendentales de mi esfera fenomenológica (Diese Erfahrungen und ibre Leistungen sind ja transzendentale Tatsachen meiner phänomenologischen Sphäre)"7.

El segundo supuesto que según Henry opera en el planteo no está especificado en Meditaciones Cartesianas, V, sino que atraviesa la obra completa de Husserl y expresa cómo me es dado el Otro según la estructura de la intencionalidad. Dice Henry: "que entre en mi experiencia quiere decir: en ese Fuera primordial donde se lanza la intencionalidad, en ese lugar de luz donde alcanza y ve todo lo que ella ve (Qu'il entre dans mon expérience, cela veut dire: dans ce Dehors primordial où se jette l'intentionalité, dans ce lieu de lumière où elle atteint et voit tout ce qu'elle voit)" 8 .

Por último, el tercer supuesto del análisis husserliano consistiría en la conjunción de los primeros dos supuestos: el otro está dado a mi experiencia primer supuesto- y se trata de una aparición noemática a título de correlato intencional -segundo supuesto-. En resumen, a juicio de Henry la quinta de las Meditaciones Cartesianas se basa en que el otro estaría dado en mí como algo trascendente. Esto determina un enfoque donde la alteridad, tal como la experimentamos, con todo el plexo de emociones que suscita la presencia o ausencia del otro cifrado en la noción de pathos-con, queda fuera de consideración, ya que una condición no afectiva no podría dar cuenta de lo afectivo de la Vida interpatética 9 .

A partir de estos supuestos y en vistas de la carencia respecto de las modalidades concretas con las que tenemos experiencia de la alteridad, Henry

fenomenología, de modo que el principio "a tanto aparecer tanto ser" implica "sin el aparecer no hay nada para nosotros" (In, 44). Sobre la fórmula de Epicuro, véase J. Warren, Facing Death. Epicurus and his Critics, Oxford, OUP, 2004.

${ }^{7}$ Hua I, 121.

8 PhM, 138. Tal afirmación surge del \# 42 de las Meditaciones Cartesianas, donde Husserl sostiene que "tenemos que conseguir ver cómo, en qué intencionalidades, en qué síntesis, en qué motivaciones se forma en mí el sentido 'otro ego' (anderes ego) y, bajo el título de 'experiencia unánime de la alteridad' (einstimmiger Fremderfabrung), se verifica como existiendo -y, a su modo, incluso como estando ahí él mismo" (Hua I, 121). ${ }^{9} \mathrm{PhM}, 141$. 
cuestiona cómo la mirada intencional, que en sí no es, podría ser condición de aquello que resulta ser necesariamente afectivo -i.e. la experiencia con el otro. De esta manera, con la intención de demostrar los límites del enfoque intencional, Henry dirigirá su crítica a los problemas detectados en la presentación husserliana: la determinación de lo propio del ego, la circularidad en la transferencia analogizante y por último las degradaciones del ego original, el cuerpo y la alteridad.

Henry rememora que en la quinta de las Meditaciones Cartesianas Husserl practica una "segunda reducción temática" -luego de la trascendental-, donde quedarán entre paréntesis todos los sentidos de mi experiencia que remiten o se hayan originado en "otros yoes". En esta esfera de propiedad queda resguardado mi cuerpo, que es órgano de mi movimiento y centro de mi orientación, así como todos los objetos que no refieran a un otro. En efecto, dice Husserl que una mediación de la intencionalidad aprehende al otro a través de la presentación de un cuerpo material o físico que, en mi esfera primordial, en mi primordialidad, se manifiesta como análogo a mi propio cuerpo ${ }^{10}$.

En virtud de la semejanza entre mi cuerpo propio y el cuerpo del otro se establece una "parificación", es decir, una síntesis de asociación de pares. No hay conocimiento del otro sino una institución originaria del sentido "cuerpo propio" y una transferencia analogizante por medio de la cual se produce la aprehensión. Así, el otro, sin ser una duplicación del yo, es una modificación intencional de mí mismo y, según Henry, "el modelo que va a guiar la autoexplicitación del Ego (l'auto-explicitacion de l'Ego) trascendental en la reflexión sobre sí, que instituye la reducción trascendental es la experiencia perceptiva del objeto (l'expérience perceptive de l'objet) [...] al cual se dirige la mirada"11. Esto es, la autoexplicitación del ego se realiza en el mismo modo de percepción. Entonces, ¿cómo este objeto intencional que me pertenece puede ser realmente otro que yo, otro trascendente con relación a mí?

Acerca de qué es lo propio del ego, Henry advierte que, en el modo de concebir la auto-donación del sujeto a sí mismo, en el enfoque intencional se trasciende la idea de un mero punto de intersección de las síntesis constitutivas y por tanto sólo la naturaleza del ego puede decir y definir qué le es propio. Sin

\footnotetext{
${ }^{10}$ Hua I, 139 y 141.

11 PhM, 144.
} 
embargo, Husserl evita esta línea exegética donde el ego determina lo propio, dado que la vincula con el riesgo de solipsismo y disocia el ego precisamente de eso que le es propio $^{12}$.

Junto con la presentación paradójica de lo propio separado del ego, Michel Henry nota una segunda situación problemática: para elucidar la esfera de propiedad del ego, Husserl no comienza por el mundo. El procedimiento requiere descartar - por abstracción- del horizonte de experiencia todo lo que es ajeno, todo lo referido a otros, todo lo que confiere a los animales su carácter de seres vivos, a los hombres su carácter de seres personales, a los objetos su conjunto de rasgos ${ }^{13}$. El resultado de esta operación es que en esta naturaleza reducida a lo propio los otros son realidades constituidas y yo un ego que al auto-elucidarme sólo estoy ante elementos constituidos, de manera que lo propio se reduce a la estructura de un mundo ${ }^{14}$. Esto se revela en el hecho de que el modelo de análisis de la alteridad no difiere del modelo de análisis de objetos, de manera que desde la perspectiva henryana implicaría aplicar la estructura de la percepción a la de "la auto-revelación inmediata de la subjetividad absoluta, con la esencia interior de la Vida (l'auto-révélation immédiate de la subjectivité absolue, à l'essence intèrieure de la vie)"15.

\section{La fenomenología material y el plano de lo inaparente}

A primera vista, las tesis henryanas parecen incompatibles con la fenomenología de cuño husserliano. Sin embargo, el enfoque que proponemos señala la inapariencia como terreno legítimamente fenomenológico y en condiciones de dialogar con provecho con los aportes que, en la fenomenología

\footnotetext{
12 PhM, 142.

13 PhM, 143: "De este modo se pone de relieve mi esfera de lo propio [Eigenheitssphäre], con una «naturaleza mía propia», diferente de la naturaleza objetiva y que incluye en ella mi cuerpo vivo [Leib], diferente de todos los demás (Ainsi se dégage ma sphère d'appartenance [Eigenheitssphäre], avec une "nature qui m'appartient 》, différente de la nature et incluant en elle mon corps organique [Leib], différent de tous les autres)".

14 PhM, 143.

15 PhM, 144.
} 
francesa y sus derivas en los nuevos realismos, se apartan o reniegan de los orígenes husserlianos. En otros lugares hemos desarrollado los elementos que llevan a plantear un nivel de análisis fenomenológico más allá de la generatividad y su atención a los fenómenos geohistóricos, culturales e intersubjetivos, de modo que junto con la estaticidad y la geneticidad complete el arco de dispositivos y fenómenos. ${ }^{16}$ En efecto, los niveles estático y genético, desarrollados explícitamente por Husserl en textos de la década de 1920, fueron complementados por el reconocimiento del ámbito generativo que se extendió a partir de la propuesta de A. Steinbock y está esbozado especialmente en los trabajos de Husserl del último período. ${ }^{17}$ Continuando este movimiento de exploración de los tipos fenoménicos, es preciso prestar atención a la esfera del exceso más allá de la generatividad. Como dimensión metahistórica, explora lo que subyace al mundo y la subjetividad a través de figuras como lo inconsciente, el sueño, el nacimiento, la muerte, el otro, la vida animal y vegetal, lo divino, etcétera ${ }^{18}$.

La fenomenología de lo inaparente describe lo que no se muestra o escapa al horizonte, lo que está más allá de la actividad intencional y por tanto altera los parámetros onto-noemáticos que sostienen la investigación en otros niveles. Para captar esta dimensión se necesita una disposición subjetiva que

${ }^{16}$ No nos detendremos aquí por obvias razones de espacio en una exposición de este punto. Remitimos para una explicitación de la fenomenología de lo inaparente y del dispositivo fenomenológico general visto desde esta perspectiva a $\mathrm{H}$. Inverso, Fenomenología de lo inaparente, Buenos Aires, Universidad de Buenos Aires, Tesis Doctoral, 2016 y "La fenomenología de lo inaparente y el problema de las vías hacia el plano trascendental", Eidos, 26, pp. 43-73, para concentrarnos aquí en las razones para conectar la dimensión de la inapariencia con la posición henryana en un ámbito fenomenológico integrado.

${ }^{17}$ Véase A. Steinbock, Home and Beyond: Generative Phenomenology After Husserl, Illinois, Northwestern University Press, 1995; A. Steinbock, "Generativity and generative phenomenology", Husserl Studies, 12, 1997 y A. Steinbock, "Husserl's Static and Genetic Phenomenology: Translator's Introduction to two Essays", Continental Philosophy Review, 31, 1998.

18 A. Steinbock, "Generativity and the Scope of Generative Phenomenology", en D. Welton, The New Husserl: A Critical Reader, Indiana, Indiana University Press, 2003, pp. 315 y ss. 
permita tratar con el exceso que subyace a toda apariencia enfatizando la radicalidad e implica una revisión de la intencionalidad y sus rasgos en un plexo donde sujeto, fenómeno y la correlación entre ambos resulta afectada en una evaluación de los límites de la correlación que realiza dentro y no fuera de la fenomenología ${ }^{19}$.

Desde esta perspectiva, las objeciones henryanas, que pretenden impugnar el dispositivo husserliano íntegro, en realidad sólo llaman la atención sobre otra dimensión exegética que no apunte al análisis constitutivo, sino a los planos asociados con las capas de excedencia -vistas de una perspectiva intencional- que subyacen y unifican a la comunidad de vivientes. La advertencia, en todo caso, consistiría en que se debe tener en cuenta esta dimensión y desplegarla explícitamente como estrato fenomenológico, sin necesidad de pensar en una impugnación de los análisis estáticos, genéticos y generativos. De este modo, las críticas asociadas al monismo y su compromiso con la intencionalidad como modo único de manifestación pueden entenderse como una circunscripción de esta modalidad a determinados estratos y un llamamiento a reconocer un fundamento más radical.

Henry mismo afirma que, "en vez de problematizar de forma radical la donación que precede a la captación explicitadora...", Husserl toma otro camino, lo cual puede interpretarse como señalamiento de la importancia del despliegue de este plano. Por tanto, la investigación de la alteridad no se limita a "saber cómo este objeto intencional que me pertenece puede sin embargo ser algo más que 'el punto de intersección de mis síntesis constitutivas' (le point d'intersection de mes synthèses constitutives); ser en cierto modo irreducible a mi ser propio, realmente otro que yo, trascendente con relación a mí”. ${ }^{20}$

En términos generales, el aporte henryano puede sintetizarse como una indicación de la pertinencia de desarrollar una fenomenología de lo inaparente. Pero para identificar sus puntos argumentales más potentes hay que desligar los términos impugnatorios e interpretarlos como una explicitación de los núcleos de complementación que requieren los desarrollos husserlianos, que

\footnotetext{
${ }^{19}$ Véase H. Inverso, "Phenomenology of the Inapparent. A Methodological Approach to Speculative Realism”, en N. Garrera Tolbert (ed.), The New Realisms, Leiden, Brill, en prensa.

$20 \mathrm{PhM}, 145$.
} 
provendrían precisamente de la investigación de la inapariencia. Cabe aclarar que la inapariencia no se opone a lo fenoménico, sino que es su cara siempre presente y fundante de latencia que en las exploraciones de Henry encuentra nuevas manifestaciones. En este sentido, la suposición de que Husserl considera la intencionalidad y su distancia intrínseca como el modo exclusivo del aparecer no resulta exagerada y pasa por alto la apertura al ámbito de lo inekstático, razón por la cual podremos sugerir que en múltiples sentidos Henry está más cerca del dispositivo husserliano de lo que cree y sus desarrollos aportan elementos de peso para el estudio de la dimensión fundante. Revisemos en esta clave el avance de la crítica henryana sobre la alteridad.

\section{Alteridad e inapariencia}

Henry afirma que Husserl comienza correctamente colocando como primer hilo conductor del análisis de la alteridad la noción de alter, de manera que, si el otro es otro yo, yo soy el ego original. Eso abre la vía hacia la expresión de una ipseidad radical, pero luego adviene la idea de que el ego operativo, el que opera la constitución, es un ego constituido, que habita el cuerpo y lo hace un organismo. Con esto se plantea una doble deriva posible de captación de la alteridad, que se plasma en un análisis constitutivo y en un análisis de la dimensión de inapariencia que funda todos los otros análisis.

Henry señala el dispositivo analógico que traza una semejanza con el cuerpo del otro y vincula dentro de mi esfera primordial ese otro cuerpo con el mío. En esa descripción detecta una circularidad, en tanto la analogía supone ya concebir al otro como un organismo. Al mismo tiempo, la parificación que forma parte de la transferencia aperceptiva falsificaría la experiencia de la alteridad, puesto que la parificación se aplica a objetos y requiere, por tanto, poner al otro como objeto y colocarme a mí mismo como tal21.

Por esta vía se sostiene que el planteo general provoca una degradación del ego original, trascendental, en yo psico-físico que adviene como "forma objetiva en el mundo de la esfera de lo mío propio (forme objective dans le monde

${ }^{21}$ PhM, 147. 
de ma sphère d'appartenance)"22. Esta degradación trae aparejadas dos más, la del cuerpo y la de la alteridad, dado que el cuerpo se vuelve mero cuerpo constituido, perdiendo los rasgos de inmanencia e ipseidad. Ego y cuerpo quedan desplazados de su radicalidad presupuesta en el análisis en términos de parificación, introduciendo una alteridad también degradada. Este diagnóstico de degradación generalizada constituye estrictamente una indicación de que determinados elementos son examinados en un plano que no es el único posible.

Por cierto, Henry dice que "cuando dos cuerpos son apercibidos en parificación representativa, [...] lejos de fundar la experiencia de la alteridad y de definirla originalmente, se la presupone (loin de fonder l'expérience d'autrui et de la définir originellement, la présuppose)" 23 . Esto implica que, existiendo un plano último y radical, Husserl realiza el análisis en una dimensión que no es esa, y así "degrada", desplaza, hace descender el plano de análisis y lo efectivamente fundante resulta una presuposición que opera de modo disruptivo, indicando que la investigación no agota los elementos en juego.

Podemos decir lo mismo de forma positiva: Husserl elige una dimensión donde predominan los elementos estáticos y genéticos del análisis de la alteridad, lo cual puede suplementarse con el análisis de la misma cuestión en régimen de inapariencia. Volviendo a la afirmación de Henry, el examen de la alteridad en términos de parificación presupone estudios más radicales si se evalúa desde un análisis no intencional. Por tanto, es diferente del que Husserl realiza en Meditaciones Cartesianas y pertenece a una dimensión distinta de hermeneusis, pero no anula su validez en el estrato al que pertenece, que no pretende ser el último y mantiene su compromiso con la estructura intencional.

En el análisis de Meditaciones Cartesianas, V, Henry detecta problemas en el modo de comprender la alteridad, dado que, en ella, a diferencia de la percepción, el objeto que soporta el sentido transferido es mi cuerpo y está siempre presente, pero el objeto sobre el que se transfiere nunca está dado sino que sólo es apresentado. Mientras la experiencia perceptiva hace reversibles los objetos en parificación, esto no sucede en la experiencia de la alteridad. En este

$22 \mathrm{PhM}, 148$.

${ }^{23} \mathrm{PhM}, 149$. 
marco, la apresentación del otro me da como co-representado su psiquismo junto con su cuerpo en un juego de apresentaciones basadas en su nexo con presentaciones mías propias ${ }^{24}$.

Henry sostiene respecto del primer aspecto que, como se ha dicho, el cuerpo quedó degradado como constituido, de manera que no da una presencia original e inmanente. Si estuviera, sería la verdadera constancia, "mientras que la presencia de mi cuerpo a mi sensibilidad en el interior de la esfera de lo mío propio no tiene nada que exija o implique su constancia, de modo que el argumento de Husserl se viene abajo (l'argument de Husserl se défait)" 25.

En realidad, este paso argumental es opaco, dado que en vistas de una crítica interna Henry ingresa en la lógica husserliana, pero a medias. El argumento requiere una patencia absoluta inconstituida como condición para que funcione la parificación. Sin embargo, él mismo explicitó antes los supuestos del planteo y señaló precisamente que la parificación se da entre objetos, de manera que la radicalidad en la concepción de lo propio, que claramente es ajena a este nivel de análisis que opta y elige enfatizar la dimensión constitutiva, implicaría quebrar toda posibilidad de parificación. En ese caso, por cierto, no habría manera de establecer un nexo entre la patencia absoluta y la apresentación del otro.

De este modo, la adopción de un modelo de revelación auto-afectiva en el seno del modelo de transferencia analogizante implica su anulación misma, y en todo caso lo que "se viene abajo" no es el análisis husserliano sino la sugerencia de modificación de Henry. Teniendo en cuenta que la meta primaria es anular todo el análisis, se puede comprender la estrategia, pero cabe notar que eso se hace al precio de hacer intervenir una condición extraña al argumento y contraria a su lógica interna, que señalaría, como venimos diciendo, una vía alternativa de examen de la alteridad que no anula la husserliana. En este sentido, una contemplación menos sesgada del procedimiento husserliano deja abierta la vía de la inapariencia.

El segundo punto que analiza Henry atiende a la imposibilidad de acceder a la experiencia de lo propio del otro, señalando que entraña dos

${ }^{24}$ PhM, 150.

${ }_{25} \mathrm{PhM}, 151$. 
significados. Por un lado, no puedo alcanzar directamente su subjetividad y me limito a apresentarla; por otro, adviene un sentido no concebido por Husserl, que indica una imposibilidad primordial de percibir intencionalmente al otro, dado que es una subjetividad absoluta y toda subjetividad originaria propia o no propia escapa a la intencionalida ${ }^{26}$. El otro no es su cuerpo intencionalmente constituido por mí, y es por tanto una irrealidad noemática, pero su Vida me está vedada, no me es dada ni en la inmanencia de mi Vida ni en la representación, y es por ello trascendencia absoluta.

El planteo en este caso, otra cara de la objeción al punto anterior, es que la Vida trascendental en tanto viviente no admite distancia ad intra y por tanto la intencionalidad íntegra pierde sentido frente a la impresionalidad. Un inicio de este tipo busca programáticamente enfatizar el plexo común de la Vida, de modo que desaparece todo el problema de la trascendencia y de los riesgos de solipsismo. Sin embargo, cabe notar que esto sucedería al precio de dar cuenta de niveles de investigación fenomenológica donde prima la auto-afección, difícilmente extrapolables a exámenes del tipo de la experiencia perceptual, donde la distancia entre subjetividad y fenómeno es parte de los datos primarios en ese plano de análisis y produce rendimientos importantes.

En este sentido, la alteridad constituye un punto que invita a tomar conciencia de la conformación de otros estratos de investigación, dado que queda resentido por ciertos aspectos, pero la simple inversión que implica sustituir la estructura intencional por una impresional corre el riesgo de disminuir la efectividad del dispositivo en su tarea de dar cuenta de fenómenos sin excedencia. Más todavía, las mismas exploraciones henryanas que salen del ámbito específico de la Vida, la carne y sus rasgos intrínsecos, no presentan en términos generales elementos propios de esta impronta, sino que se avienen mejor a un marco de intencionalidad, bajo el modelo de una conciencia orientada y preocupada por lo que se le aparece sin que la supuesta impresionalidad impacte en el método ni los resultados obtenidos en estos ámbitos.

El último punto que Henry sumaba a su objeción era la apelación al carácter de la apresentación del otro a partir de su nexo con presentaciones perceptivas del cuerpo-objeto percibido, que entrañaría la paradoja de tener

$26 \mathrm{PhM}, 151$. 
que recurrir al cuerpo degradado a su objetualidad de modo que se sustituye el acceso a la subjetividad por el del acceso a un objeto. Esta operación oscurecería toda captación de la intersubjetividad viva y patética, en tanto queda atada a las leyes de la presentación perceptiva y no a las leyes del "pathos de las subjetividades en su co-pertenencia interna al Fondo de la Vida (les lois du pathos de ces subjectivités dans leur co-appartenance interne au Fond de la vie)" ${ }^{27}$. Se trata de otra cara de la misma crítica, que condena el intento de acceder a la alteridad a través de una fenomenología de la percepción que no la agota ${ }^{28}$. Volvamos a insistir en que nada en el dispositivo fenomenológico pretende que la alteridad quede de este modo agotada, como muestran los despliegues de la generatividad, donde la intersubjetividad está en primer plano, y deben sumarse todavía las investigaciones de lo inaparente, que exploran todos los fenómenos en su aspecto de latencia y excedencia.

Para ejemplificar la propuesta de una fenomenología de la alteridad que no apele a la percepción Henry propone dos casos de comunidades, contando con que la comunidad tiene lugar en un plano anterior a aquel en que se constituyen las ipseidades y las subjetividades monádicas, de manera tal que estrictamente no hay intersubjetividad sino comunidad trascendental. En primer lugar, sugiere el caso de una comunidad de admiradores de Kandinsky que ni siquiera se han encontrado nunca, pero los une la contemplación de la obra que admiran. Esto no es algo objetivo, dado que pertenece a la dimensión de lo invisible, radicalmente subjetivo e inmanente, de modo tal que prima "el pathos de la obra (le pathos de l'oeuvre)" donde se aúnan Kandinsky en tanto creador y todos los que ingresan a esta comunidad patética ${ }^{29}$.

En segundo lugar, la comunidad con los muertos, que presenta huellas en el recuerdo provocadas por los que hemos conocido, pero las excede en tanto no son sólo recuerdo sino "ese pathos en nosotros que se sustrae a nuestros actos de pensamiento y que los determina secretamente (ce pathos en nous soustrait à nos actes de pensé et les déterminant secrètement)" 30 . Esto es, hay una

\footnotetext{
${ }^{27}$ PhM, 153.

28 PhM, 153.

${ }^{29}$ PhM, 154.

${ }_{30}$ PhM, 154.
} 
comunidad con los muertos que opera efectivamente y no es reductible a la lógica de la percepción. Al mismo tiempo, el resto de los muertos que no hemos conocido conforman esta comunidad de humanidad en nosotros ${ }^{31}$.

La categoría misma de muertos se desdibuja si, siguiendo a Henry, los muertos no son los que han dejado este mundo, sino que "todavía viven muchos que podríamos volver a ver y, de este modo, percibir de nuevo, de tal forma que dicho volver a ver no alteraría para nada su muerte en nosotros, haciéndola únicamente más sensible (la rendant seulement plus sensible)" ${ }^{32}$. La muerte no es, entonces, simplemente la ausencia de Vida, sino un estado más complejo que convive con ella en la inmanencia patética y tiende a quedar obturada en una época tecnocientífica que en su interpretación de todo en términos objetuales no tiene modos de dar cuenta de la comunidad con ella.

No obstante, estrictamente, el caso de la comunidad con los muertos no es un buen ejemplo para impugnar los desarrollos acerca de la empatía, dado que Husserl mismo señaló que la empatía según el modelo básico no puede aplicarse al caso de los muertos o incluso al de los todavía no nacidos, que cumplen una función fundamental en la proyección de las comunidades políticas, pero sí puede funcionar a través de modificaciones intencionales de los otros presentes ${ }^{33}$. Para estos casos Husserl plantea que mediante estas modificaciones intencionales pueden volverse familiares y a ellos se accede con la clave de la intersubjetividad que rige la exploración generativa, apelando a la constitución de sentido histórico y la dimensión narrativa de la cadena de generaciones que constituye la tradición y su asociación con lo propio ${ }^{34}$.

Siguiendo, entonces, a Husserl y desplegando el sentido ínsito en su tratamiento, podemos decir que Henry detecta precisamente la multiplicidad de dimensiones de análisis y la inconveniencia de absolutizar alguno de ellos,

\footnotetext{
31 PhM, 154.

$32 \mathrm{PhM}, 154$.

${ }^{33}$ R. Walton, "Teleología y teología en Edmund Husserl”, Estudios de filosofía, 45, 2012, p. 327.

${ }^{34}$ Hua XV, 472-475, 218 ss. y Hua XV, 145. Sobre las nociones de comunidad y pathos-con, véase G. Fainstein Lamuedra, "Alteridad, intersubjetividad y comunidad en la vida en el pensamiento de Michel Henry”, Investigaciones fenomenológicas, 3, 2011, pp. 186-190.
} 
como se desprende igualmente del tratamiento husserliano visto en su integralidad, de modo tal que la intersubjetividad puede verse como empatía, como plexo generativo, y eventualmente también $-\mathrm{y}$ ahí estaría el aporte henryano- como fenómeno con excedencia, donde se enfoca la dimensión auto-afectiva de la Vida o la fuente última de donación. En cualquier caso, se trata de niveles complementarios de análisis que no deberían provocar denegaciones de los desarrollos husserlianos, respecto de los cuales las vertientes críticas que intentan demolerlos terminan siendo, por el contrario, refuerzos importantes. Más todavía, radicalizar no es absolutizar, y los alcances de la fenomenología material en cuanto a fundamento justifican los análisis intencionales de los otros estratos y nunca los anulan, de modo tal que es preciso avanzar en una explicitación de la relación entre lo fundante y lo fundado.

Henry sostiene que la percepción debería ser sustituida por el afecto, que no se funda en un modo de presentación noética ni noemática, es decir, asociada con la intencionalidad y la constitución, sino que se remonta a la "donación que consiste en la afectividad trascendental y, así, en la Vida misma (une donation consistant dans l'affectivité transcendantale et ainsi dans la vie elle-même)" 35 , vía para alcanzar "el ser real del otro en mí (l'être réel de l'autre en mor)" ${ }^{36}$. En esta perspectiva la comunidad es una experiencia refractaria a la representación, a la manera de una experiencia que, entre otros ejemplos, se asemeja al estadio hipnótico donde la intencionalidad queda suspendida, de modo tal que la comunidad resulta el pathos ciego de la Vida donde los tres elementos de sí mismo, otro y fondo se dan indiferenciados.

La presentación noemática de la alteridad supone, por tanto, un doble fracaso. Por un lado, al reducir el ser real a una presentación noemática fuera de mí lo convierte en una irrealidad, mero "correlato de una mención intencional (le corrélat d'une visée intentionnelle)" ${ }^{37}$. Henry menciona que Husserl reconoció esta operación y por eso insistió en que la comunidad originaria no es una nada, sino que "un ser está con otro en comunidad intencional" 38 ,

\footnotetext{
35 PhM, 155.

$36 \mathrm{PhM}, 155$.

37 PhM, 156.

${ }^{38}$ Hua I, 157.
} 
infiriendo de esta declaración el indicio de un fracaso admitido o al menos de un inconveniente reconocido y suturado con una declaración de intenciones. Por el contrario, notemos que podría tomarse la afirmación de Husserl como una afirmación que se plenifica en los estudios de la generatividad.

El segundo aspecto del fracaso de la presentación noemática de la alteridad está asociado con la separación de las mónadas, que implica una distanciación igualmente abismal de sus esferas de lo propio, hasta el punto de que "reducida a la esfera de lo suyo propio y a lo que de este modo le es propio, cada 'mónada' se encuentra de hecho desligada de lo que le es más propio (dessaisie de qui lui est le plus propre), de su propio pathos y del movimiento de la Vida en ella (de son propre pathos et du mouvement de la vie en elle) que, como pulsión y como Deseo, la lanza ya hacia el otro" ${ }^{39}$. Este planteo lleva a objetar como una confusión en los supuestos la sugerencia husserliana de que hay un enigma que anida en la distancia intermonádica, pero que "el enigma sólo surge cuando ya han sido distinguidas las dos esferas originales, y es ésta una distinción que supone que la experiencia del otro ya ha llevado a cabo su obra" 40 .

Si la distinción es tal, se plantea, debería detener todo análisis de la experiencia del otro o bloquearlo retrospectivamente en tanto afectado por el enigma. La alternativa, claramente a estas alturas, es aceptar que la percepción tiene un fondo de donación que la excede, precisamente como sugiere Henry, pero esto no conforma un peligro ni un fracaso de la presentación noemática de la alteridad sino un campo de investigación adicional. Este enigma es el que adviene en las coordenadas que adopta la formulación husserliana, pero no son las únicas posibles, y su examen se plenifica solamente en otra dimensión de análisis. En efecto, Henry sostiene que la fenomenología intencional fracasa en su comprensión del lazo entre los vivientes, dado que es la Vida -y no la intencionalidad- quien en su inmanencia radical relaciona lo que ella misma produce. Podría decirse que entre lo que produce está la intencionalidad y que el despliegue de los análisis intencionales debería ser visto como un modo de su misma auto-donación. En este sentido es tan legítimo enfocar la fuente última, el fondo, como las dinámicas locales para las cuales la intencionalidad es un modo posible de abordaje. Donde Henry enfatiza la heterogeneidad

${ }^{39}$ PhM, 156. Véase además G. Fainstein Lamuedra, op. cit., pp. 184-185.

$40 \mathrm{PhM}, 207$. La referencia corresponde a Hua I, 150. 
irreductible de la inmanencia respecto de la manifestación trascendente cabe abrir la posibilidad de una convivencia primaria que afecta especialmente al método fenomenológico, en tanto despliega mecanismos de abordaje de distintos ámbitos de la fenomenalidad, desde la estaticidad hasta su fundamento en lo inmanente.

\section{Corolarios}

Este recorrido invita a suscribir la opinión henryana según la cual "la fenomenología desconfía de las explicaciones últimas, dedicándose en primer lugar a los problemas de la descripción. Pero una descripción que deja escapar lo esencial de la 'cosa misma', en este caso el pathos de toda intersubjetividad concreta (le pathos de toute intersubjectivité concrète), no puede legitimarse ni siquiera sobre el plano de la facticidad" 41 . Esto es, la fenomenología describe en los planos que puede describir y considera incluso el modo de atisbar lo que no se muestra, de modo tal que es posible trocar esta condena contra la presentación noemática en la aceptación de sus términos como un ejercicio de estudio de la alteridad en el marco intencional constitutivo. Este marco contiene incluso marcas de los "enigmas" que deben ser resueltos en otros planos donde la dinámica entre sí mismo, otro y fondo, en su radicalidad como elementos para pensar la alteridad, cobran sentido. Para profundizar la crítica, Henry condena en bloque los desarrollos husserlianos generativos sobre intersubjetividad sintetizando todos los aportes en términos de una "concepción pulsional de la comunidad". Con ello se confundiría el movimiento inmanente de la Vida con una proyección extática que lo aniquila y restituye la oposición sujeto-objeto, que Henry asocia sin más a la intencionalidad.

Así, la crítica afirma que el ámbito de la generatividad no es lo suficientemente radical. Ante eso, en la línea de la distinción entre generatividad y Generatividad que sugiere Steinbock ${ }^{42}$, cabe salir de este equívoco instaurando

\footnotetext{
${ }^{41} \mathrm{PhM}, 158$.

42 Véase A. Steinbock, Home and Beyond: Generative Phenomenology After Husserl, Illinois, Northwestern University Press, 1995, pp. 315 y ss., donde considera propios de la "generatividad" los fenómenos de lo intersubjetivo, histórico y cultural y propios de la "Generatividad" los fenómenos con excedencia.
} 
para este último campo una dimensión de estudio de lo inaparente que se coloque en clara situación de diálogo y cooperación con los otros análisis, y abandone las fricciones del momento de instauración de un espacio disciplinar. Como pasa con el despliegue inicial de un espacio de estudio, primero debe ganar su terreno con tomas de distancia respecto de lo previo, que muchas veces se traducen en enunciados polémicos afirmados en la negatividad, para mostrar el nuevo elemento a través lo que no es. Este recurso es útil porque aprovecha lo que ya se conoce de los campos previos, pero si esta etapa de negatividad se prolonga comienza a provocar dudas sobre su identidad, es decir acerca de si se trata de un ámbito novedoso o un desvío rupturista, como ha pasado en las críticas codificadas en términos de 'giro teológico' o 'giro ontoteológico' ${ }^{43}$.

La salida de esta situación, en el mejor de los casos, viene de la mano de una redefinición de los términos disciplinares generales, de modo tal que cada elemento recree su relación con el resto haciendo lugar a una definición positiva del nuevo campo que co-accione con el material previo. En este caso, las derivas del giro y los intentos de la fenomenología no intencional, así como todas aquellas exploraciones de la excedencia, pueden dejar de ser desvíos que se vuelven y atacan el suelo previo, para pasar a encontrar su espacio, definidas positivamente como fenomenología de lo inaparente, en una fenomenología potenciada en sus alcances.

Recibido: 01/2017; aceptado: 06/2017

${ }^{43}$ Véase D. Janicaud, Le Tournant théologique de la phénoménologie française, Combas, Éd. de l'Éclat, 1991; J. Schrijvers, Ontotheological Turnings? The Decentering of the Modern Subject in Recent French Phenomenology, New York, Author House, 2011. 